\title{
Readjustable midurethral sling (REMEEX system) in obese women
}

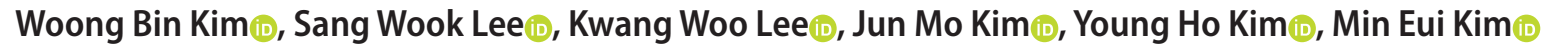 \\ Department of Urology, Soonchunhyang University Bucheon Hospital, Soonchunhyang University College of Medicine, Bucheon, Korea
}

Purpose: To evaluate the success rate and patient satisfaction with the readjustable midurethral sling (REMEEX system) for the treatment of stress urinary incontinence (SUI) with intrinsic sphincter deficiency (ISD) or recurrent SUI in obese and non-obese women.

Materials and Methods: Between August 2009 and August 2015, 70 patients who treated with the REMEEX system were stratified into normal, overweight and obesity groups according to body mass index. Objective surgical outcomes were evaluated using a 1-hour pad test that was performed 3 months after surgery. The subjective outcomes and degree of patient satisfaction were evaluated 3 months and 1 year after surgery.

Results: Twenty-six normal weight, 31 overweight, and 13 obese women were included in the study. The objective cure rate determined using the 1-hour pad test revealed that 11 women (42.3\%) were cured and 15 (57.7\%) had improved in the normal weight group, respectively, compared with $16(51.6 \%)$ and 15 (48.4\%) in the overweight group and $6(46.2 \%)$ and 7 (53.8\%) in the obese group, respectively $(p=0.78)$. One year after surgery, the subjective success rate was $91.5 \%$ in the normal weight group, $93.5 \%$ in the overweight group and $92.3 \%$ in the obese group. A total of $84.7 \%, 77.4 \%$, and $77.0 \%$ of normal weight, overweight and obese women were very satisfied or satisfied 1 year after surgery, respectively. All groups showed similar success rates and satisfaction. Conclusions: The REMEEX procedure is equally effective in obese and normal weight women with ISD-type SUI or recurrent SUI.

Keywords: Obesity; Suburethral slings; Urinary incontinence

This is an Open Access article distributed under the terms of the Creative Commons Attribution Non-Commercial License (http://creativecommons.org/licenses/by-nc/4.0) which permits unrestricted non-commercial use, distribution, and reproduction in any medium, provided the original work is properly cited.

\section{INTRODUCTION}

Obesity, which is associated with a number of potential health risks, has become a remarkable problem worldwide. Many risk factors are associated with the occurrence of stress urinary incontinence (SUI) [1,2], including obesity, because it increases the pressure in the abdomen [3,4]. Obesity is associated with increased pressure on the pelvic floor, which results in damage to the nerves and muscle and a higher prevalence of SUI than occurs in non-obese individuals [5]. Weight has a greater impact on SUI (including mixed incontinence) than urge incontinence, and urinary incontinence improves significantly with weight loss [6].

Midurethal slings, such as retropubic tension-free vaginal tape (TVT) and transobturator tape (TOT) procedures, are the standard treatments for female SUI. However, in cases of SUI due to intrinsic sphincter deficiency (ISD), which has a low treatment rate, there is an increasing trend

Received: 13 March, 2019 - Accepted: 15 July, 2019

Corresponding Author: Young Ho Kim (iD https://orcid.org/0000-0003-3959-0928

Department of Urology, Soonchunhyang University Bucheon Hospital, Soonchunhyang University College of Medicine, 170 Jomaru-ro, Wonmi-gu, Bucheon 14584 , Korea

TEL: +82-32-621-5463, FAX: +82-32-621-5018, E-mail: yhkuro@schmc.ac.kr 
toward treatment with midurethral sling surgery using a new device. The readjustable midurethral sling (REMEEX system) was introduced as a new device that combines the advantages of a less-invasive approach and the opportunity of sling re-adjustment to increase the success rate and overcome the complications generally reported after the positioning of other compressive pubovaginal slings [7]. Recently, a number of authors published their experience of the REMEEX procedure for the treatment of ISD-type SUI; they achieved remarkable results in terms of cure and complication rates. However, no studies have assessed the surgical outcomes in obese patients, who have a higher prevalence of SUI and more severe symptoms. In this study, we compare the subjective and objective outcomes of overweight, obese, and non-obese patients 1 year after implantation of the REMEEX system.

\section{MATERIALS AND METHODS}

\section{Patients}

From August 2009 to August 2015, we retrospectively analysed the medical records of 104 female patients who had undergone REMEEX surgery for the treatment of SUI due to ISD or recurrent SUI in a single tertiary medical facility. The inclusion criteria were patients who had undergone REMEEX surgery and complained of SUI due to ISD or had previously undergone anti-incontinence surgery but in whom urinary incontinence had recurred. Patients who complained of previous urge incontinence symptoms, presented any pelvic organ prolapse and for whom followup records were missing, were excluded. A total 70 of the 104 patients were included in this study. All patients underwent history-taking, anthropometric measurements, physical examination, 1-hour pad test, uroflowmetry and urodynamic study to identify the type of urinary incontinence. Patient data were recorded in a retrospective database that was approved by Soonchunhyang University Bucheon Hospital Institutional Review Board (approval number: SCHBC 201903-015), and informed consent was waived because of the study design. The data were abstracted from the patient charts and entered into the database. ISD was defined as a Valsalva leak-point pressure (VLPP) $<60 \mathrm{~cm} \mathrm{H}_{2} \mathrm{O}$ or a maximal urethral closure pressure (MUCP) $<20 \mathrm{~cm} \mathrm{H}_{2} \mathrm{O}$. Patients were divided into normal, overweight and obesity groups according to their body mass index (BMI). BMI was calculated as weight in kilograms divided by the square of height in meters; the World Health Organization (WHO) definitions of 'overweight' as a BMI $>25 \mathrm{~kg} / \mathrm{m}^{2}$ and 'obesity' as a BMI $>30$ $\mathrm{kg} / \mathrm{m}^{2}$ were employed.

\section{Surgical technique}

The REMEEX system consists of a suburethral polypropylene prosthesis $(35 \times 12 \mathrm{~mm})$ that is connected to a pressureadjusting device (varitensor) by two traction threads. The patient was placed in the dorsal lithotomy position under general anaesthesia and an 18-Fr. Foley catheter was inserted. A $4-\mathrm{cm}$ abdominal transverse incision was made at the midline, two fingers above the pubic symphysis, the fat was dissected, and the fascia of the anterior rectal abdominal muscles was exposed. Traction threads were implanted in the abdominal site through the anterior vaginal wall at the midurethral level. Subsequently, the bladder integrity was evaluated by cystoscopy. After determining that the bladder was intact, the threads were connected to the varitensor and the manipulator was turned clockwise until it was positioned approximately two fingers' distance over the rectus fascia (Figs. 1, 2). When the varitensor was positioned at its proper location, the surgeon sutured the opening site but kept the incision area open where the manipulator was connected. This approach allowed the manipulator to remain
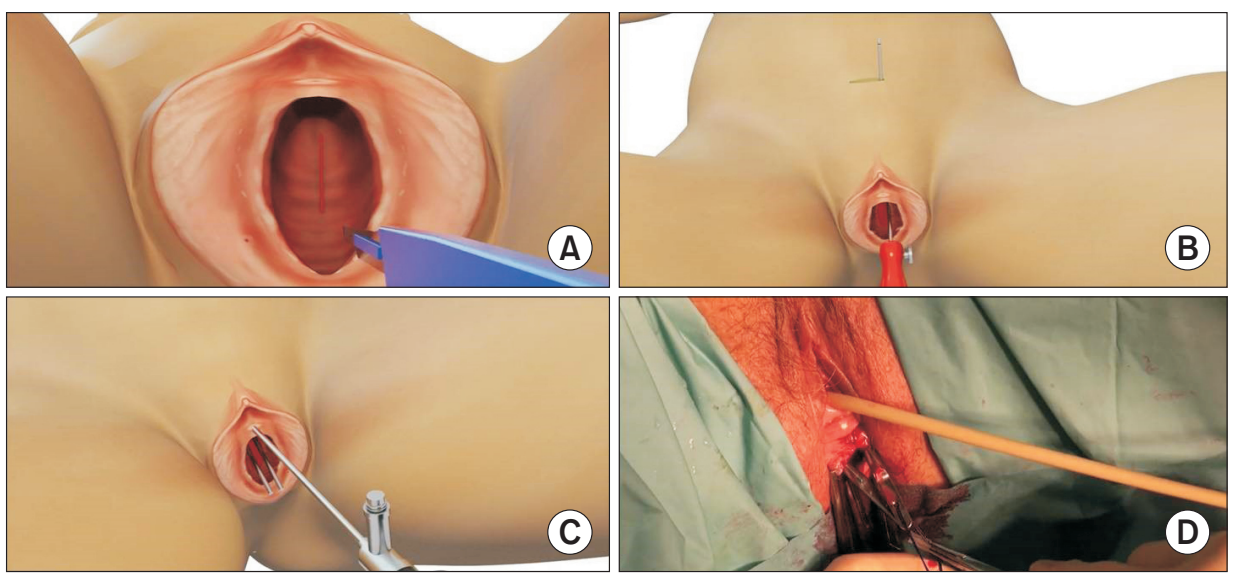

Fig. 1. (A) Make an incision in the anterior vaginal wall at the mid-urethral level. (B) Insert the two needles through the vaginal incision until reaching the abdominal site. (C) Check the bladder integrity by means of a cystoscopy. (D) Connect the traction threads to the needles. Images from Neomedic International. 
perpendicular to the skin. The day after surgery, $250 \mathrm{~mL}$ of saline was injected into the bladder, the urethral catheter was removed and the patient was instructed to perform a Valsalva manoeuver and cough while standing. If a leak was still observed, two clockwise turns were made twice a day on the manipulator until continence was reached (Fig. 3). The patient was subsequently instructed to void urine in the toilet and the residual urine volume was determined using a portable sonar. If the residual urine volume was $<100 \mathrm{~mL}$, the manipulator could be disconnected from the varitensor. However, if the residual urine volume was $>100 \mathrm{~mL}$, the manipulator was turned anti-clockwise to decrease the sling support. The varitensor stayed implanted above the rectus fascia as a permanent regulation mechanism that could be used to readjust the sling during follow-up care as needed.

\section{Postoperative evaluations}

Postoperative follow-up visits occurred at 1,3 , and 12 months after surgery. Objective patient outcomes were determined according to the results of 1-hour pad tests performed 3 months after surgery as follows: $<2 \mathrm{~g}$ of urine leakage was considered a 'cure', 2 to $50 \mathrm{~g}$ of urine leakage was considered an 'improvement' and $>50 \mathrm{~g}$ of urine leakage was considered 'failure'. Patients completed a severity index for urinary incontinence at 3 months and 1 year after surgery, and the results were defined as follows: a state in which no urinary incontinence was present was defined as 'cured', a state in which incontinence symptoms were very rare and inconspicuous or the patient was satisfied with the surgical outcome was 'improvement'. The presence of severe urinary incontinence after surgery or a patient complaining of dissatisfaction with the outcome of the surgery was de- fined as 'failure' [8].

The success rate was defined as the sum of the cure and improvement rates. The subjective satisfaction of the patients was determined by selecting one of the five levels of the Likert scale (very satisfied, satisfied, neither satisfied nor unsatisfied, unsatisfied and very unsatisfied) at 1-year follow-up.

\section{Postoperative complications}

We reviewed the medical record of the patients to investigate the intraoperative and postoperative complications. All complications were classified according to the modified Clavien complication classification system.

\section{Statistical analysis}

The baseline characteristics and postoperative outcomes were compared according to body weight. The frequencies and proportions of each categorical variable were compared

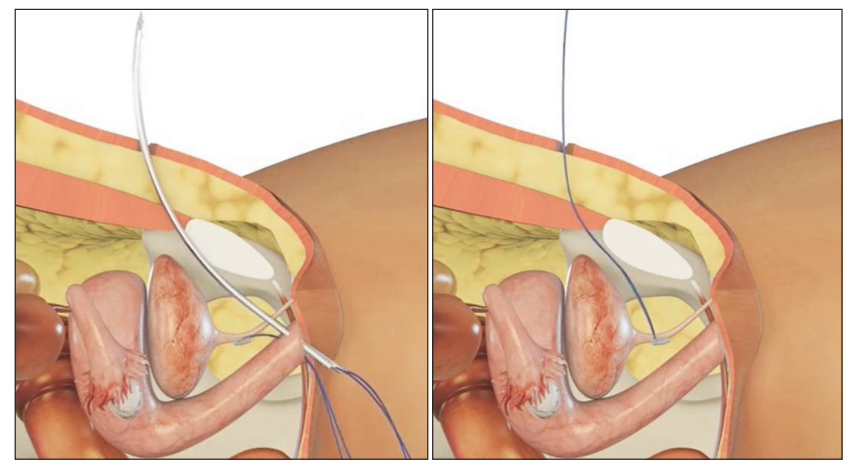

Fig. 2. Traction threads were implanted in the abdominal site through the anterior vaginal wall at the midurethral level (sagittal view). Images from Neomedic International.
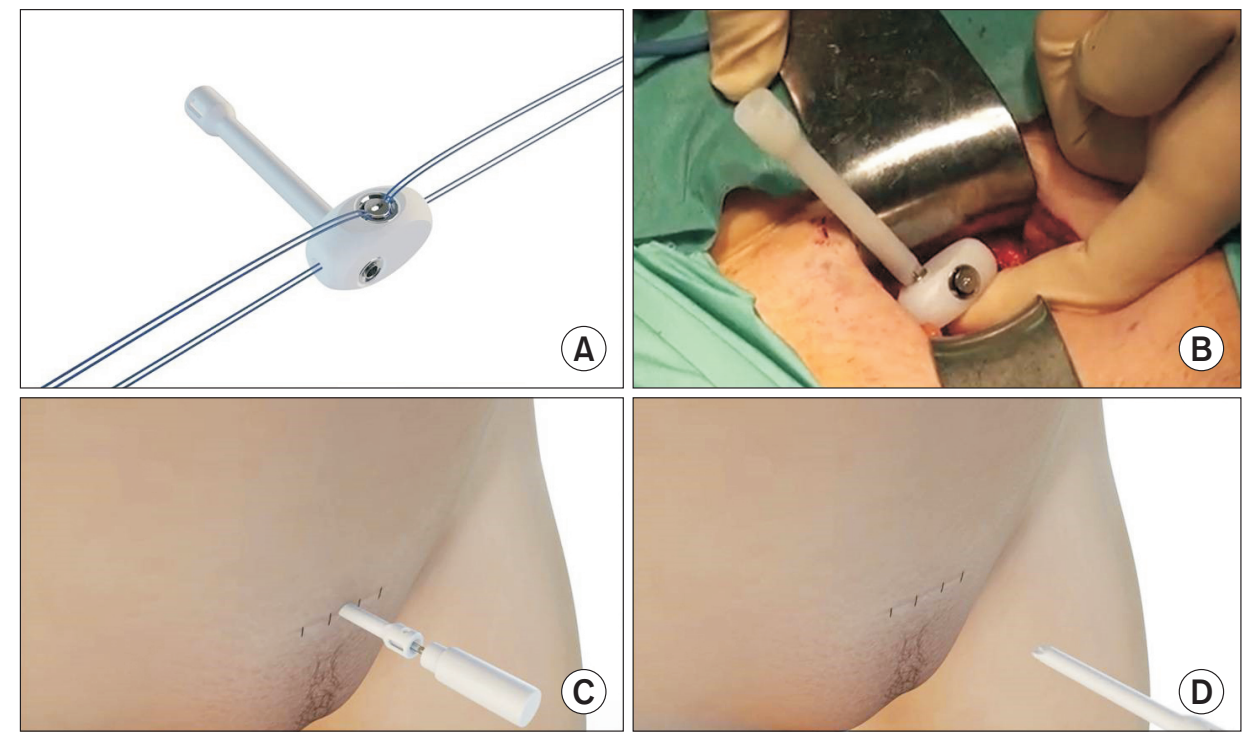

Fig. 3. (A) Passing traction threads through lateral holes of the varitensor. (B) Turning of the varitensor clockwise so it rests tension free on the fascia of rectus abdominis muscles. (C) Adjusting the device by turning the manipulator. (D) Manipulator disconnector. Images from Neomedic International. 
using chi-square test or Fisher's exact tests, as appropriate. For continuous variables, means and standard deviations were compared using one-way analysis of variance (ANOVA) after normality and variance-equivalence tests. For abnormally-distributed continuous variables, median values and interquartile ranges were compared using Kruskal-Wallis tests. All statistical tests were conducted at a two-sided significance level of 0.05 using $R$ (version 3.13; The $R$ Foundation for Statistical Computing, Vienna, Austria).

\section{RESULTS}

Of the 104 patients who underwent REMEEX surgery, 70 patients who were followed up for 1 year were included in this study. Of these, 64 (91.4\%) were diagnosed with SUI due to ISD and $6(8.6 \%)$ had recurrence after undergoing midurethral anti-incontinent surgery. There were 26 normal weight women, 31 overweight women, and 13 obese women. The baseline characteristics of the patients are summarised in Table 1. The mean BMIs of patients in the normal, overweight, and obese groups were $23.0 \pm 1.5 \mathrm{~kg} / \mathrm{m}^{2}, 27.1 \pm 1.2 \mathrm{~kg} / \mathrm{m}^{2}$ and $31.9 \pm 1.9 \mathrm{~kg} / \mathrm{m}^{2}$, respectively. A comparison of the characteristics among groups found no statistically significant differences in age, gravidity, parity, obstetrical history and the presence of menstruation ( $p>0.05$ ).

The mean VLPP value in preoperative urodynamic study was $48.2 \pm 7.4 \mathrm{~mm} \mathrm{Hg}$ in the normal weight group, $50.9 \pm 5.5 \mathrm{~mm} \mathrm{Hg}$ in the overweight group and $52.4 \pm 6.1 \mathrm{~mm}$ $\mathrm{Hg}$ in the obese group. The mean results of the 1-hour pad test were $44.3 \pm 34.4 \mathrm{~g}$ in the normal weight group, $42.5 \pm 29.8 \mathrm{~g}$ in the overweight group and $30.8 \pm 13.4 \mathrm{~g}$ in the obese group. There was no significant difference in the results of the pre- operative VLPP and 1-hour pad test among groups. ( $\mathrm{p}=0.086$ and 0.099 , respectively).

Table 2 shows the clinical outcomes of the REMEEX procedure. The results of the 1-hour pad tests performed 3 months after surgery, which were considered the objective outcome, revealed that urine leakage was $2.6 \pm 2.5 \mathrm{~g}$ in the normal weight group, $1.8 \pm 1.8 \mathrm{~g}$ in the overweight group and $1.5 \pm 1.7 \mathrm{~g}$ in the obese group $(\mathrm{p}=0.331)$. The objective cure rate according to the 1-hour pad test was 11 patients (42.3\%) cured and 15 (57.7\%) improved in the normal weight group, 16 (51.6\%) cured and 15 (48.4\%) improved in the overweight group. Six (46.2\%) cured and 7 (53.8\%) improved in the obese group $(\mathrm{p}=0.78)$. No patients in any group sustained $>50 \mathrm{~g}$ urine leakage. The success rate (the sum of cure and improvement) at 3 months after surgery was 100\% in all groups. However, the 1-year postoperative, success rate was $91.5 \%$ in the normal weight group, $93.5 \%$ in the overweight group and $92.3 \%$ in the obese group. All groups exhibited similar success rates. A total of $84.7 \%, 77.4 \%$, and $77.0 \%$ of normal weight, overweight and obese women were very satisfied or satisfied 1 year after surgery. Conversely, 15.4\% of the normal weight group, $22.6 \%$ of the overweight group and $23.1 \%$ of the obese group were 'neither satisfied nor unsatisfied', 'unsatisfied' or 'very unsatisfied' 1 year after surgery. Patient satisfaction was not significantly different among the BMI groups ( $\mathrm{p}=0.948$ ).

In our study, a total of 34 cases of complications occurred in 26 patients (37.1\%). According to the modified Clavien system, 19 complications (27.1\%) were classified with grade I complications, 4 complications (5.7\%) were classified as grade II, and 11 complications (15.7\%) were classified with grade III (Table 3). Three bladder perforation (4.3\%) were

Table 1. Baseline characteristics according to body weight

\begin{tabular}{|c|c|c|c|c|c|}
\hline Variable & Total $(n=70)$ & Normal $(n=26)$ & Overweight $(n=31)$ & Obese $(n=13)$ & p-value \\
\hline Age (y) & $55.7 \pm 6.5$ & $55.8 \pm 6.8$ & $55.9 \pm 6.4$ & $55.1 \pm 6.8$ & 0.789 \\
\hline BMI $\left(\mathrm{kg} / \mathrm{m}^{2}\right)$ & $26.4 \pm 3.5$ & $23.0 \pm 1.5$ & $27.1 \pm 1.2$ & $31.9 \pm 1.9$ & $<0.001$ \\
\hline Gravidity & $4.0(3.0-5.0)$ & $4.0(3.0-5.0)$ & $3.0(3.0-4.5)$ & $4.0(3.0-5.0)$ & 0.788 \\
\hline Parity & $2.0(2.0-3.0)$ & $2.0(2.0-3.0)$ & $2.0(2.0-2.0)$ & $2.0(2.0-3.0)$ & 0.710 \\
\hline C-section & $3(4.3)$ & $1(3.8)$ & $2(6.5)$ & $0(0.0)$ & 1.000 \\
\hline Menopause & $57(81.4)$ & $22(84.6)$ & $24(77.4)$ & $11(84.6)$ & 0.787 \\
\hline Type of UI & & & & & 0.328 \\
\hline ISD & $64(91.4)$ & $22(84.6)$ & $29(93.5)$ & $13(100.0)$ & \\
\hline Recurrent & $6(8.6)$ & $4(15.4)$ & $2(6.5)$ & $0(0.0)$ & \\
\hline VLPP (mm Hg) & $50.2 \pm 6.5$ & $48.2 \pm 7.4$ & $50.9 \pm 5.5$ & $52.4 \pm 6.1$ & 0.086 \\
\hline Pad test $(\mathrm{g})$ & $41.0 \pm 29.5$ & $44.3 \pm 34.4$ & $42.5 \pm 29.8$ & $30.8 \pm 13.4$ & 0.099 \\
\hline
\end{tabular}

Values are presented as mean \pm standard deviation, median (interquartile range) for continuous variables, or number (\%) for categorical variables. BMI, body mass index; UI, urinary incontinence; ISD, intrinsic sphincter deficiency; VLPP, Valsalva leak-point pressure.

p-values were calculated using one-way ANOVA or Kruskal-Wallis tests for continuous variables and chi-square or Fisher's exact tests for categorical variables, as appropriate. 
Table 2. Postoperative outcome after REMEEX according to body weight

\begin{tabular}{|c|c|c|c|c|c|}
\hline Variable & Total $(n=70)$ & Normal $(n=26)$ & Overweight $(n=31)$ & Obese $(n=13)$ & $\mathrm{p}$-value \\
\hline \multicolumn{6}{|l|}{ Objective outcome } \\
\hline Pad test $(\mathrm{g})$ & $2.0 \pm 2.1$ & $2.6 \pm 2.5$ & $1.8 \pm 1.8$ & $1.5 \pm 1.7$ & 0.331 \\
\hline Categorized by pad test & & & & & 0.78 \\
\hline Cured $(0$ to $1 \mathrm{~g})$ & $33(47.1)$ & $11(42.3)$ & $16(51.6)$ & $6(46.2)$ & \\
\hline Improved ( 2 to $50 \mathrm{~g}$ ) & $37(52.9)$ & $15(57.7)$ & $15(48.4)$ & $7(53.8)$ & \\
\hline Failed $(>50 \mathrm{~g})$ & $0(0.0)$ & $0(0.0)$ & $0(0.0)$ & $0(0.0)$ & \\
\hline \multicolumn{6}{|l|}{ Subjective outcome } \\
\hline Surgical success at 3 months & & & & & 1.000 \\
\hline Cured & $61(87.1)$ & $23(88.5)$ & $27(87.1)$ & $11(84.6)$ & \\
\hline Improved & $9(12.9)$ & $3(11.5)$ & $4(12.9)$ & $2(15.4)$ & \\
\hline Failed & $0(0.0)$ & $0(0.0)$ & $0(0.0)$ & $0(0.0)$ & \\
\hline Surgical success at 1 year & & & & & 1.000 \\
\hline Cured & $56(80.0)$ & $21(80.8)$ & $25(80.6)$ & $10(76.9)$ & \\
\hline Improved & $9(12.9)$ & $3(11.5)$ & $4(12.9)$ & $2(15.4)$ & \\
\hline Failed & $5(7.1)$ & $2(7.7)$ & $2(6.5)$ & $1(7.7)$ & \\
\hline Patient's satisfaction at 1 year & & & & & 0.948 \\
\hline Very satisfied & $28(40.0)$ & $10(38.5)$ & $12(38.7)$ & $6(46.2)$ & \\
\hline Satisfied & $28(40.0)$ & $12(46.2)$ & $12(38.7)$ & $4(30.8)$ & \\
\hline Neither satisfied nor unsatisfied & $7(10.0)$ & $2(7.7)$ & $4(12.9)$ & $1(7.7)$ & \\
\hline Unsatisfied & $6(8.6)$ & $2(7.7)$ & $2(6.5)$ & $2(15.4)$ & \\
\hline Very unsatisfied & $1(1.4)$ & $0(0.0)$ & $1(3.2)$ & $0(0.0)$ & \\
\hline
\end{tabular}

Values are presented as mean \pm standard deviation for continuous variables, or number (\%) for categorical variables. p-values were calculated using one-way ANOVA for continuous variables and chi-square or Fisher's exact tests for categorical variables, as appropriate.

Table 3. Postoperative complications

\begin{tabular}{|c|c|c|c|c|c|}
\hline & Complication & Total $(n=70)$ & Normal $(n=26)$ & Overweight $(n=31)$ & Obese $(n=13)$ \\
\hline \multirow[t]{4}{*}{ I } & Bladder perforation & $3(4.3)$ & $2(7.7)$ & $1(3.2)$ & $0(0.0)$ \\
\hline & Hematoma & $6(8.6)$ & $3(11.5)$ & $2(6.5)$ & $1(7.7)$ \\
\hline & Acute urinary retention & $5(7.1)$ & $2(7.7)$ & $2(6.5)$ & $1(7.7)$ \\
\hline & De novo urgency & $5(7.1)$ & $1(3.8)$ & $3(9.7)$ & $1(7.7)$ \\
\hline \multirow[t]{2}{*}{ II } & Wound infection & $2(2.9)$ & $1(3.8)$ & $1(3.2)$ & $0(0.0)$ \\
\hline & Persistent suprapubic pain & $2(2.9)$ & $0(0.0)$ & $2(6.5)$ & $0(0.0)$ \\
\hline \multirow[t]{2}{*}{ IIla } & Recurrent stress urinary incontinence & $11(15.7)$ & $4(15.4)$ & $5(16.1)$ & $2(15.4)$ \\
\hline & Urinary retention & $0(0.0)$ & $0(0.0)$ & $0(0.0)$ & $0(0.0)$ \\
\hline IIIb & Infection, sling removed & $0(0.0)$ & $0(0.0)$ & $0(0.0)$ & $0(0.0)$ \\
\hline
\end{tabular}

Values are presented as number (\%).

observed during surgery and were solved by reinsertion of trocar immediately. There were 6 hematomas (8.6\%), which were managed by conservative treatment without additional intervention. In the Foley catheter removal on the day after surgery, acute urinary retention occurred in 5 patients (7.1\%). Three of these patients were resolved naturally, but two patients had early readjustment on the second day of operation. Five patients (7.1\%) experienced de novo urgency, requiring treatment with anticholinergic drugs. None of the patients complained of recurrence of urinary incontinence until 3 months postoperatively. However, 11 patients (15.7\%) complained of recurrence of urinary incontinence during follow-up, and these patients required delayed sling readjustment under local anesthesia. Fortunately, none of the patients in our study needed removal of the remex system due to the occurrence of surgical site infection. There was no need for statistical analysis because of the small number of complications.

\section{DISCUSSION}

Since the first description of TVT as a modified sling 
surgery method by Ulmsten et al. [9] in 1996, many reports have been published on the effects of mid-urethral tape surgery. In a multi-centre study by Ulmsten et al. [10], who reported more than 1 year follow-up data from patients undergoing mid-urethral sling tape surgery, $91 \%$ of patients were cured and 7\% of patients had improved. In 2001, Delorme [11] described an alternative approach using TOT to avoid major complications. The cure rates achieved with TVT and TOT procedures were similar, ranging from $90 \%$ to $95 \%$ [12]. Thus, midurethral sling surgery is widely used as a standard treatment for stress incontinence in women; it is simple to perform, yields a high treatment success rate, low complication rate and is highly cost-effective.

Clinically, women with ISD have more severe incontinence and a lower surgical success rate than do women with stress incontinence and normal urethral function [13]. In addition, the surgical failure rates increase four- to six-fold when there is evidence of ISD [14]. The United States and European guidelines recommend urethral bulking agents, suburethral slings and artificial urethral sphincters for the treatment of SUI with ISD [15,16]. In cases of SUI caused by ISD, most tension-free anti-incontinence devices have low or ineffective therapeutic efficacy, and fixed urethra ISD has a very lower therapeutic efficacy and the highest failure rate [17,18].

Many studies have revealed that SUI due to ISD is challenging for many urologists because of the relatively low success rate of treatment. Recently, middle urethral sling operations using the REMEEX system were performed for the treatment of SUI due to ISD. With the REMEEX system, the operator can immediately adjust the urethral sling tension and also perform delayed readjustments in cases of treatment failure to achieve a lower rate of complications. Reports of the surgical outcomes and complications of the REMEEX procedure have recently been published. Moreno Sierra et al. [19] followed a group of 683 women with mixed incontinence (30.2\%), ISD (73.1\%) and recurrent SUI (35.7\%) who underwent the REMEEX procedure for a mean of 23 months (range, 6-93 months). The authors reported that the cure rate was $92.2 \%$, with $6.9 \%$ reporting improvement and 0.9\% reporting failure. Eighty patients (11.7\%) underwent readjustment between 6 and 8 months after surgery. Errando et al. [20] prospectively reported a mean follow-up of 38 months in 125 patients with SUI because of ISD (55/125, $44.0 \%)$ and recurrent SUI (70/125, 56.0\%) who underwent REMEEX surgery. The pad test results revealed that $87 \%$ of the patients were cured, $6 \%$ needed re-adjustment and $7 \%$ needed re-adjustment but refused the procedure because they were satisfied with the operation. Giberti et al. [21] used the REMEEX system on 30 patients with SUI and ISD for a mean of 60.6 months (range, 22-96 months). They reported that $26(86.7 \%)$ patients were cured, $2(6.7 \%)$ had improved, and $2(6.7 \%)$ had failed treatment. Two patients (6.7\%) required sling tension readjustment. Park et al. [22] reported the surgical outcomes obtained using the REMEEX system (mean follow-up, 27.6 months; range, 14-56 months). They reported that the cure, improvement and failure rates were $89.2 \%$ (91/102 patients), 5.9\% (6/102) and 4.9\% (5/102), respectively. In addition, $80.0 \%$ of patients were very satisfied or satisfied with the operation results at the 1-year follow-up. In addition, recent published research results are summarized in Table 4 [19-25]. In the current study, the short-term results of 70 patients with SUI (64 cases of SUI due to ISD and 6 recurrent SUI cases) who underwent REMEEX surgery revealed a subjective cure rate of $92.9 \%$ and an objective cure rate of $100 \%$.

Obesity is an independent risk factor for the development of SUI; however, its mechanism is unclear. In a study of 2,589 women aged 30 to 59 years, Mommsen and Foldspang [4] reported that BMI was positively correlated with urinary incontinence, independently of other risk factors, especially SUI. Higher intrabdominal pressures have been observed in patients with a greater BMI, with a mean $4.9 \mathrm{~mm}$ $\mathrm{Hg}$ pressure observed in non-obese patients compared with

Table 4. Comparison of the published series of female urinary incontinence patients who underwent the Remeex surgery

\begin{tabular}{lcccclc}
\hline \multicolumn{1}{c}{ Author } & Year & No. & $\begin{array}{c}\text { Follow-up } \\
(\mathbf{m o})\end{array}$ & $\begin{array}{c}\text { Cure } \\
\text { rate (\%) }\end{array}$ & $\begin{array}{c}\text { Complication } \\
\text { rate (\%) }\end{array}$ \\
\hline Moreno Sierra et al. [19] & 2006 & 683 & 23 & 92.2 & No leakage on CST with full bladder (250 to 300 mL) & 27.6 \\
Errando et al. [20] & 2010 & 125 & 38 & 87 & Dry in CST, pad-test and UDS and/or no need of pads \\
Giberti et al. [21] & 2011 & 30 & 60.6 & 86 & Dry in CST and/or pad weight 0 to $1 \mathrm{~g}$ & 8.8 \\
Park et al. [22] & 2015 & 102 & 27.6 & 89.2 & Pad weight <2 g, subjective (very satisfied) \\
Mantovani [25] & 2017 & 55 & 60 & 90.0 & Dry in CST and/or pad weight 0 to $1 \mathrm{~g}$. \\
Chung and Yoo [23] & 2017 & 151 & 43.9 & 59.8 & No leakage complaint, subjective (very satisfied) \\
Errando-Smet et al. [24] & 2018 & 205 & 89 & 71.7 & Dry in CST, pad-test and UDS and/or no need of pads & 28.8 \\
\hline
\end{tabular}

CST, cough stress test; UDS, urodynamic studies. 
$8.9 \mathrm{~mm} \mathrm{Hg}$ in morbidly obese patients [26]. The increased abdominal pressure in obese patients is thought to contribute to the development of SUI by increasing the bladder pressure, increasing the pressure at maximum bladder capacity, decreasing the pressure transmission from the bladder to the urethra when coughing and reducing VLPP [3,26-28]. Obesity-induced neurogenic effects on the pelvic floor may also contribute to urethral dysfunction and the resulting UI [3].

There is concern that even if the midurethral sling is highly effective for the treatment of SUI, its efficacy may be reduced in overweight or obese patients. Killingsworth et al. [29] reported the results of patients who underwent TVT (195 patients; 68 normal weight, 65 overweight, and 62 obese). At the 1-year fullow-up, $18 \%, 14 \%$, and $19 \%$ of patients in the obese, overweight and normal weight groups experienced SUI symptoms, respectively; there were no statistically significant differences among groups. More recently, Brennand et al. [30] reported the results of a randomized controlled study that evaluated the effects of BMI on the objective and subjective cure rate for 12 months after midurethral sling surgery. Sixty-one obese and 121 normal weight patients were enrolled. The objective and subjective cure rates were lower in the obesity group than in the normal weight group ( $67.8 \%$ vs. $85.6 \%, p=0.006$ and $70.7 \%$ vs. $85.8 \%, p=0.016$; respectively). However, there was no difference in the quality of life, as assessed using validated questionnaires, between the two groups [30]. Therefore, the results of midurethral sling operations in obese patients have been well documented, but the results are controversial because they differ from study to study.

To our knowledge, no studies have compared the surgical outcomes of midurethral sling surgery using the REMEEX system according to BMII. In the current study, there were no differences in surgical outcome using the REMEEX system in patients with ISD-type SUI or recurrent SUI according to BMI; there was also no difference in patient satisfaction.

The current study does have some limitations. First, it was not a prospective controlled trial. However, we did rely on prospective data collected for a clinical database using standardized surgical protocols. This allowed us to ensure that all women had the same perioperative and follow-up assessments, which, in our opinion, strengthens the outcome of the analysis despite the retrospective design. Second, this study includes only short-term follow-up data. Although there were no differences among groups at 1-year after surgery, the overweight and obese patients have consistently high pressure in the pelvic area, which suggests that the long-term success rate might decrease. Therefore, later studies on the long-term results are needed.

\section{CONCLUSIONS}

The current study demonstrated that the REMEEX procedure achieves similar outcomes in women with ISD or recurrent SUI, regardless of obesity. Both obese and non-obese women had sustained cure rates at the 1-year follow-up and were satisfied with the outcome. We conclude then that REMEEX seems to be an effective and safe procedure for stress incontinence, regardless of BMI. Nevertheless, long-term follow-up results should also be obtained.

\section{CONFLICTS OF INTEREST}

The authors have nothing to disclose.

\section{ACKNOWLEDGMENTS}

This study was supported by the Soonchunhyang University Research Fund.

\section{REFERENCES}

1. Bortolotti A, Bernardini B, Colli E, Di Benedetto P, Giocoli Nacci G, Landoni M, et al. Prevalence and risk factors for urinary incontinence in Italy. Eur Urol 2000;37:30-5.

2. Yarnell JW, Voyle GJ, Sweetnam PM, Milbank J, Richards CJ, Stephenson TP. Factors associated with urinary incontinence in women. J Epidemiol Community Health 1982;36:58-63.

3. Cummings JM, Rodning CB. Urinary stress incontinence among obese women: review of pathophysiology therapy. Int Urogynecol J Pelvic Floor Dysfunct 2000;11:41-4.

4. Mommsen S, Foldspang A. Body mass index and adult female urinary incontinence. World J Urol 1994;12:319-22.

5. Rafii A, Daraï E, Haab F, Samain E, Levardon M, Deval B. Body mass index and outcome of tension-free vaginal tape. Eur Urol 2003;43:288-92.

6. Whitcomb EL, Subak LL. Effect of weight loss on urinary incontinence in women. Open Access J Urol 2011;3:123-32.

7. Morgan DM, Lewicky-Gaupp C, Dunn RL, Jayaraman G, Fenner DE, Delancey JO, et al. Factors associated with urge urinary incontinence after surgery for stress urinary incontinence. Female Pelvic Med Reconstr Surg 2011;17:120-4.

8. Sandvik H, Hunskaar S, Seim A, Hermstad R, Vanvik A, Bratt $H$. Validation of a severity index in female urinary incontinence and its implementation in an epidemiological survey. J Epidemiol Community Health 1993;47:497-9. 
9. Ulmsten U, Henriksson L, Johnson P, Varhos G. An ambulatory surgical procedure under local anesthesia for treatment of female urinary incontinence. Int Urogynecol J Pelvic Floor Dysfunct 1996;7:81-5; discussion 85-6.

10. Ulmsten U, Falconer C, Johnson P, Jomaa M, Lannér L, Nilsson CG, et al. A multicenter study of tension-free vaginal tape (TVT) for surgical treatment of stress urinary incontinence. Int Urogynecol J Pelvic Floor Dysfunct 1998;9:210-3.

11. Delorme E. [Transobturator urethral suspension: mini-invasive procedure in the treatment of stress urinary incontinence in women]. Prog Urol 2001;11:1306-13. French.

12. Mellier G, Benayed B, Bretones S, Pasquier JC. Suburethral tape via the obturator route: is the TOT a simplification of the TVT? Int Urogynecol J Pelvic Floor Dysfunct 2004;15:227-32.

13. Schierlitz L, Dwyer PL, Rosamilia A, Murray C, Thomas E, De Souza A, et al. Effectiveness of tension-free vaginal tape compared with transobturator tape in women with stress urinary incontinence and intrinsic sphincter deficiency: a randomized controlled trial. Obstet Gynecol 2008;112:1253-61.

14. Guerette NL, Bena JF, Davila GW. Transobturator slings for stress incontinence: using urodynamic parameters to predict outcomes. Int Urogynecol J Pelvic Floor Dysfunct 2008;19:97102.

15. Dmochowski RR, Blaivas JM, Gormley EA, Juma S, Karram MM, Lightner DJ, et al. Update of AUA guideline on the surgical management of female stress urinary incontinence. J Urol 2010;183:1906-14.

16. Thüroff JW, Abrams P, Andersson KE, Artibani W, Chapple $\mathrm{CR}$, Drake MJ, et al. EAU guidelines on urinary incontinence. Eur Urol 2011;59:387-400.

17. Lee KS, Choo MS, Doo CK, Han DH, Lee YS, Kim JY, et al. The long term (5-years) objective TVT success rate does not depend on predictive factors at multivariate analysis: a multicentre retrospective study. Eur Urol 2008;53:176-82.

18. Smith AL, Karp DR, Aguilar VC, Davila GW. Repeat versus primary slings in patients with intrinsic sphincter deficiency. Int Urogynecol J 2013;24:963-8.

19. Moreno Sierra J, Marqués Queimadelos A, Araño Beltran P, De La Fuente Pérez P, Cerezuela Requena JF, Cortés Otero E, et al. [Spanish registry of the TRT Reemex system in women with stress urinary incontinence (SUI)]. Arch Esp Urol 2006;59:16974. Spanish.

20. Errando C, Rodriguez-Escovar F, Gutierrez C, Baez C, Araño $\mathrm{P}$, Villavicencio $\mathrm{H}$. A re-adjustable sling for female recurrent stress incontinence and sphincteric deficiency: Outcomes and complications in 125 patients using the Remeex sling system. Neurourol Urodyn 2010;29:1429-32.

21. Giberti C, Gallo F, Cortese P, Schenone M. The suburethral tension adjustable sling (REMEEX system) in the treatment of female urinary incontinence due to 'true' intrinsic sphincter deficiency: results after 5 years of mean follow-up. BJU Int 2011;108:1140-4.

22. Park BH, Kim JC, Kim HW, Kim YH, Choi JB, Lee DH. Midterm efficacy and complications of readjustable midurethral sling (Remeex system) in female stress urinary incontinence with recurrence or intrinsic sphincter deficiency. Urology 2015;85:79-84.

23. Chung JW, Yoo ES. Efficacy and safety of a readjustable midurethral sling (Remeex system) for stress urinary incontinence with female voiding dysfunction. Investig Clin Urol 2017;58:127-33.

24. Errando-Smet C, Ruiz CG, Bertrán PA, Mavrich HV. A readjustable sling for female recurrent stress incontinence and intrinsic sphincteric deficiency: long-term results in 205 patients using the Remeex sling system. Neurourol Urodyn 2018;37:1349-55.

25. Mantovani F. ReMeEx device (External Mechanical Regulator) for female stress urinary incontinence: a critical review of a single-operator, long-term experience on implants and readjustments. Urologia 2017;84:102-5.

26. Noblett KL, Jensen JK, Ostergard DR. The relationship of body mass index to intra-abdominal pressure as measured by multichannel cystometry. Int Urogynecol J Pelvic Floor Dysfunct 1997;8:323-6.

27. Brieger G, Korda A. The effect of obesity on the outcome of successful surgery for genuine stress incontinence. Aust N Z J Obstet Gynaecol 1992;32:71-2.

28. Dwyer PL, Lee ET, Hay DM. Obesity and urinary incontinence in women. Br J Obstet Gynaecol 1988;95:91-6.

29. Killingsworth LB, Wheeler TL 2nd, Burgio KL, Martirosian TE, Redden DT, Richter HE. One-year outcomes of tensionfree vaginal tape (TVT) mid-urethral slings in overweight and obese women. Int Urogynecol J Pelvic Floor Dysfunct 2009;20:1103-8.

30. Brennand EA, Tang S, Williamson T, Birch C, Murphy M, Robert M, et al.; Calgary Women's Pelvic Health Research Group. Twelve-month outcomes following midurethral sling procedures for stress incontinence: impact of obesity. BJOG 2015;122:1705-12. 